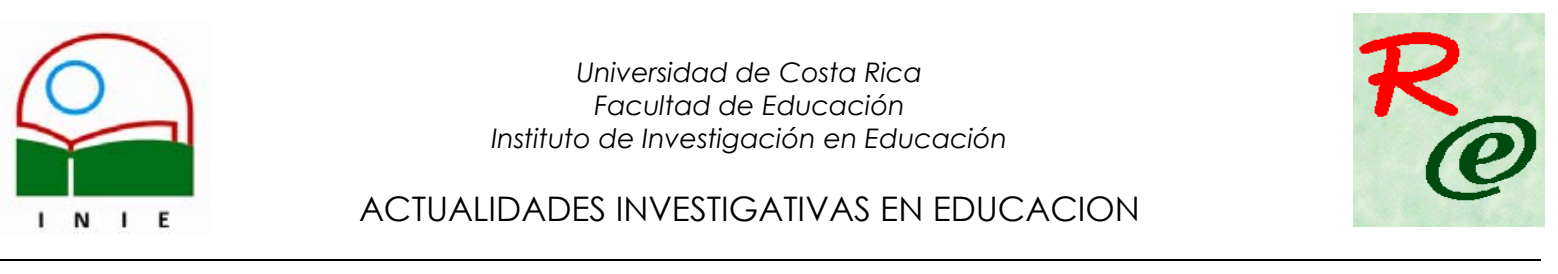

\title{
SUEÑO Y REALIDAD: EXPECTATIVAS PERSONALES Y RETOS SOCIALES
}

\section{DREAM AND REALITY: PERSONAL EXPECTATIONS AND SOCIAL CHALLENGES}

Toda persona tiene todos los derechos y libertades proclamados en esta Declaración, sin distinción alguna de raza, color, sexo, idioma, religión, opinión política o de cualquier otra índole, origen nacional o social, posición económica, nacimiento o cualquier otra condición (artículo 2, inciso 1. ${ }^{\circ}$ Declaración Universal de los Derechos Humanos, 1948).

\begin{abstract}
Mónica Arias Monge ${ }^{1}$
Resumen: El artículo se refiere al relato de la experiencia de vida de una persona con deficiencia visual, que después de vencer muchos obstáculos encuentra un camino que la conduce a la búsqueda de su razón de ser y de estar en el mundo.

Se trata de un artículo dónde la autora realiza un análisis introspectivo, a partir de sus relaciones con un marco de referencia y de contexto cultural, legal y político, y contrastándolo con las diferentes etapas de su desarrollo intelectual, profesional, cultural y social. En este aspecto resulta interesante cómo se enfatiza en las diferentes posturas sociales, unas vinculadas a la amistad y la relación familiar, otras que constituyen barreras que condicionan la accesibilidad y participación social y que responden a la falta de educación, sensibilidad y conciencia, y por último otras más esperanzadoras, que en forma solidaria promueven un convivio más asentado en la concertación y en el pluralismo, en el amor al prójimo y en el reconocimiento de las diferencias que todos los seres humanos poseemos.

Entre sus relatos y vivencias pedagógicas y culturales, se refiere a la ausencia de apoyo institucional y a la importancia de las relaciones de cooperación basadas en vínculos afectivos, las cuales le permiten alcanzar sus objetivos académicos. Actualmente, cursa el segundo año del Doctorado en Pedagogía. Doctorado Diversidad y Cambio en Educación: Políticas y Prácticas, de la Universidad de Barcelona.

Resalta la incongruencia que se da en Costa Rica, en haber logrado estándares de primer orden en la formación académica de personas con discapacidad, expectativas que resultan insatisfechas en el campo laboral, con lo cual se produce una obstaculización de la devolución de la inversión social.

Palabras clave: PERSONAS CON DISCAPACIDAD/ EDUCACIÓN INCLUSIVA/ EDUCACIÓN Y TRABAJO/ EXPERIENCIA DE VIDA/ DIVERSIDAD E INCLUSIÓN SOCIAL
\end{abstract}

Abstract: The article is the account of a visually-impaired person's life experience, a person who after conquering many obstacles finds a path to its reason of being and existing in this world.

This is a story in which the author makes a self-examining analysis that gauges her existence, from a cultural, legal and political context or frame of reference, opposable to its personal life in the different stages of its intellectual, professional, cultural and social development. In this aspect, it's interesting how the different social outlooks are highlighted; some are linked to friendship and the family relationships, and others that constitute barriers to social accessibility and participation, barriers that respond to the lack of education, sensibility and awareness. And finally, some other more auspicious circumstances that in a spirit of solidarity stimulate coexistence based on compromise and pluralism, in love towards one neighbor and in acknowledging the differences all human beings possess between themselves.

In its pedagogic and cultural stories and life experiences, the author refers to the absence of institutional support and to the importance of the cooperation relationships based on affective bonds, which in turn have allowed the author reach its academic goals. Currently, the author is at the second year of its Doctorate Degree in Pedagogy, Diversity and Change in Education, Policies and Practices at the University of Barcelona.

The article also highlights the contradictory situation in Costa Rica of having achieved first-order standards in the academic teaching of people with disabilities, to then have unfulfilled expectations when the alumni enter the working class. This problem hinders the reaping of the fruits that social investment on special education represented in the first place.

Key words: DISABLED PEOPLE/ SOCIAL INCLUSION/ EDUCATION AND LABOR/ DIVERSITY AND SOCIAL INCLUSION/ INCLUSIVE EDUCATION/ LIFE EXPERIENCE/

1 Estudiante del Doctorado en Diversidad y Cambio en Educación:

Políticas y Prácticas de la Universidad de Barcelona.

Correo electrónico: monicaariasm@hotmail.com

Artículo recibido: 10 de marzo, 2006

Aprobado: 27 de abril, 2006 
Después de 57 años de promulgada la Declaración Universal de los Derechos Humanos, el debate de ayer, de siempre y de hoy, por la democratización, la igualdad, la inclusión, la eliminación de barreras a la participación, conduce a la reflexión de si estamos asistiendo a un cambio en el accionar del conjunto de la sociedad o solamente hay una toma de postura enmascarada por el disimulo social, únicamente con el propósito de satisfacer a grupos de poder político.

Tradicionalmente la sociedad ha construido y desarrollado las estructuras de participación con base en la homogeneidad. Es así como se han creado clasificaciones, escalas, grupos diferenciales y niveles, que potencian o limitan el grado de participación de las personas en función del grupo al que pertenecen.

Las barreras de acceso y participación aparecen por medio de una interacción entre las personas y sus contextos, la sociedad, la política, las instituciones, las culturas y las circunstancias sociales y económicas que afectan a sus vidas. Estas barreras de acceso y participación social se constituyen como limitantes del potencial individual y ponen de manifiesto la complejidad del grado de riesgo, a escala emocional, económica y social, en que se encuentran las personas que, según los estándares de clasificación no se consideran normales o parte de una comunidad en mayoría o con poder.

¿Hay igualdad? ¿Puede haber igualdad? ¿Debe haber un cambio? ¿Cuál? ¿Por qué? ¿Para quién? $\mathrm{Y}$ ¿desde quién se debe producir el cambio?

En el intento por organizar y construir una respuesta a estos planteamientos, me encontré con la necesidad de escribir y de contar mi camino, un camino que no es único, pero tampoco es el de todos, un camino que no es largo, pero tampoco corto, un camino que no es sencillo, pero tampoco complicado, un camino que simplemente es.

Las cuestiones referentes a las relaciones y al contexto que han mediado en mi proceso formativo y de desarrollo personal, y mi situación dentro de la escala de clasificación de persona con discapacidad y de mujer, me llevan a la reflexión de mi escolarización, de mis aprendizajes y experiencias, desde dentro y desde afuera. 
Nací hace 30 años, en San José de Costa Rica. Soy la segunda de cinco hermanos y la única mujer. Dos de mis hermanos y yo, desde el nacimiento tenemos retinosis pigmentaria, la cual es una enfermedad degenerativa de la retina, que produce una disminución progresiva del campo visual y dificulta la visión en lugares de poca iluminación, hasta producir la ceguera total.

En mi caso, el proceso de acceso y participación social ha estado fundamentalmente marcado por principios, valores, vínculos y sentimientos forjados en el seno de mi familia. Desde mi niñez, dentro de mi núcleo familiar, como en la familia más extensa, siempre fui Mónica y al igual que al resto de mis hermanos o primos, nunca se me limitó o se me condicionó, con un "no, porque usted no puede". Por el contrario, siempre se me motivó y se me orientó como a cualquier otro miembro para lograrlo.

Una auténtica comunidad es un grupo de individuos que han aprendido a comunicarse entre ellos con sinceridad, cuyas relaciones son profundas y que han adquirido un compromiso para vivir juntos y hacer nuestras las situaciones de los demás Stainbach, S., Stainbach, W. (1999, p. 22).

Cuando leí esta definición, reconocí de inmediato en ella a mi familia. Recordé cientos de situaciones que compartimos y experimentamos juntos. Si bien es cierto reconozco a mi familia en esta definición, puedo afirmar que el compromiso de un proyecto de vida y los vínculos afectivos se construyeron en el tiempo, en la convivencia, en la discordancia y la comunión, y que no terminan de formarse porque están en permanente construcción.

Hace treinta y dos años la información médica que existía acerca de la enfermedad era mínima, a los pocos meses de nacer mi hermano mayor, mi madre notó en él algo extraño en su comportamiento al compararlo con el de otros niños de su misma edad. Su preocupación la condujo a buscar un diagnóstico médico, el resultado fue retraso mental severo, mi hermano supuestamente no podría hablar ni caminar. Pero a los 11 meses la realidad era otra, hablaba casi perfectamente algo inusual en un niño de esa edad y empezaba a caminar tomado de la mano. Fue entonces cuando mi madre descubrió que algo era distinto en su visión. Evidentemente, el diagnóstico era erróneo porque las pruebas las habían realizado en un lugar con poca iluminación. 
La "lotería" genética se había jugado, rompiendo las estadísticas, tres de cinco hijos superaba en mucho lo esperado. Una "lotería" genética que no tenía antecedentes y en donde la ausencia de una explicación científica generaba, en lo más profundo, sentimientos de culpabilidad, que tuvieron que irse diluyendo con el tiempo y el proceso de aceptación de la realidad.

No logro precisar el momento de mi niñez en el que comprendí que mi visión era diferente a la de los demás. Solo sé que fue pronto, no tendría yo ni cinco años. Creo que el ser consciente de mi diferencia, no fue algo que me causara temor o rechazo, porque puedo decir con certeza que me sentía feliz, yo me asumía y me veía como a cualquier otra niña. Por supuesto, la felicidad era producto de la sensación de aceptación, que partía de la comparación simple de realidades cercanas y de los sentimientos de amor a los que estaba expuesta por parte de mi familia.

En mi niñez, mi madre me enseñó las cosas que se enseña a una niña, aprendí a vestirme, a seleccionar mi ropa, a ordenar mis cosas, a hacer la cama, y a participar y compartir de los juegos e intereses de otros niños. Paralelamente, me fue motivando a descubrir el mundo de las letras, de los colores y de la imaginación.

En el momento de iniciar mi vida escolar, se hizo evidente la preocupación de mi familia, con respecto al incierto futuro que nos esperaba a mis hermanos y a mí, en una sociedad poco tolerante con las diferencias.

En los últimos años de la década de los setenta, en Costa Rica, el sistema educativo fundamentaba su estructura y accionar, en los fines, principios y valores democráticos que el sistema político constitucional del país.

Artículo 78:

La educación preescolar y la general básica son obligatorias. Estas y la educación diversificada en el sistema público son gratuitas y costeadas por la Nación. En la educación estatal, incluida la superior, el gasto público no será inferior al seis por ciento $(6 \%)$ anual del producto interno bruto, de acuerdo con la ley, sin perjuicio de lo establecido en los artículos 84 y 85 de esta Constitución. El Estado facilitará la prosecución de estudios superiores a quienes carezcan de recursos pecuniarios. La adjudicación de las becas y los auxilios estará a cargo del Ministerio del ramo, por 
medio del organismo que determine la ley (Constitución Política de la República de Costa Rica, 1949).

Pero, a finales de los años setenta, en Costa Rica, a niños como mis hermanos y yo, muchas familias les negaban el derecho a la educación y para las que no lo hacían el sistema preveía una escuela llamada de enseñanza especial o las llamadas aulas diferenciadas. Entonces los principios de obligatoriedad de la educación plasmados en la Constitución Política, ¿eran un ideal o una realidad?

La decisión y el empeño de mis padres, a la hora de iniciar mi vida académica, empezó por intentar inscribirnos en una escuela normal, en un sistema regular. Se opusieron firmemente a inscribirnos en una escuela de enseñanza especial y, a las llamadas aulas diferenciadas. Tenían muy clara nuestra diferencia y nuestra capacidad. Sabían que íbamos a vivir en un mundo real y no en una burbuja de cristal.

El recorrido fue largo, las escuelas privadas, hasta las religiosas, se opusieron a nuestro ingreso, recomendando a mis padres que lo mejor era dejarnos en casa. Finalmente lograron inscribirnos en una escuela pública gracias a la sensibilidad y calidad humana de la Directora.

Sin embargo, los docentes no tenían ni la formación ni el apoyo institucional, ni la sensibilidad para apoyar a niños con discapacidad dentro de sus aulas. Creo que los maestros me percibían con temor e inquietud, mientras que para mí eran seres distantes, que en cierta forma también generaban miedo y dolor, ya que con frecuencia se prestaban a las burlas y motes impuestos por mis compañeros; y porque hacían pocos intentos por acercarse a enseñar. Es decir, existía un filtro mental (percepción), tanto del docente como mío, que afectaba nuestra forma de relacionarnos y de actuar.

Para mí el asistir a la escuela era un asunto más de relaciones sociales, de enfrentarme con la realidad y de descubrir lo que había fuera de mi hogar. El aprendizaje del programa escolar lo realizaba en casa, con la ayuda de mi madre, ella era la que adaptaba los materiales y la que pacientemente explicaba el contenido. 
En ese mar de dificultad que parecía ser mi vida escolar, he de reconocer que la firmeza y exigencia de mi padre; el disimulo del sufrimiento, la motivación, la comunicación abierta y sincera, propiciados por mi madre, y el compartir las experiencias con mis hermanos y la sensibilidad de algunos niños que desinteresadamente me dieron la mano, fueron elementos fundamentales para salir avante. Recuerdo esos años de la escuela con tristeza y dolor, no me sentía parte de nada, solo mi casa y mi familia me permitían sentir una sensación de pertenencia. La escuela no me gustaba, cada día contaba las horas para salir de ahí, horas que se hacían eternas, impaciente por llegar a mi casa y aprender. Con mi madre y mis hermanos aprendí poesías, nombres de estrellas, países, capitales, historia universal, y todo lo que encontrábamos en las enciclopedias que mi padre nos compraba, aprendí a pintar sin importar los colores que utilizaba, a escribir sin importar que me saliera de la línea. Tenía muchas ganas de aprender, quizá porque desde antes de iniciar la educación preescolar había asistido con mi madre a la Universidad, mientras terminaba sus estudios de Farmacia y supongo que el observar su esfuerzo y su constancia me enseñaron a valorar y amar el aprender.

En 1985, el afán de mis padres por encontrar una solución médica a la enfermedad, los condujo a plantearse la posibilidad de visitar una de las clínicas oftalmológicas más prestigiosas del mundo, en Barcelona. Los recursos económicos de mi familia eran limitados, pero el pretexto de una beca de estudios de mi padre nos permitió atravesar el Atlántico y vivir dos años en Barcelona y cumplir el objetivo.

La visita a la Clínica Oftalmológica Barraquer no dio una respuesta esperanzadora, por primera vez teníamos un diagnóstico claro; era retinosis pigmentaria, y el avance de la enfermedad era inevitable. Sin embargo, la experiencia de vivir dos años en Barcelona fue fundamental en la construcción de relaciones más sólidas entre los miembros de mi familia y en mi proceso de escolarización.

La oportunidad de recibir, por primera vez, apoyo escolar institucional por parte de la Organización Nacional de Ciegos Españoles (ONCE), con recursos materiales y humanos especializados, me permitió descubrir un mundo de materiales y de maestros desconocido hasta entonces para mí, que facilitaban y propiciaban mi participación social y mi aprendizaje. 
Un par de campamentos organizados por la ONCE me dieron la oportunidad de compartir con niños con deficiencias visuales; esa vivencia me permitió explorar la realidad de otros niños con características similares a la mía. Pero desde entonces me pregunto: ¿son actividades como esta segregadoras? $\mathrm{O}$, ¿son una necesidad para encontrar identidad?

La experiencia en Barcelona me permitió el enfrentarme con una realidad social y cultural distinta a la de mi país, afectando y exigiendo una mayor capacidad de adaptación y de ajuste al medio. ¿Era yo la que tenía que adaptarme o ajustarme? ¿Por qué? ¿Ajustarme y adaptarme a una cultura era la forma de no sentirme distinta, de sentirme integrada, de sentirme parte del lugar dónde vivía? Y, ¿en qué cambió el medio con mi presencia?

Al regresar a Costa Rica inicié mis estudios de educación secundaria, en el Liceo Laboratorio de la Universidad de Costa Rica, el cual era un colegio público en donde los programas y metodologías empleados eran de carácter experimental. Estaba claro el concepto de enseñar algo más que contenidos, ajustándose a las limitaciones del currículo oficial propuesto por el Ministerio de Educación Pública.

En la filosofía de trabajo predominaban los valores de libertad y respeto; los ejes fundamentales del programa eran el análisis, la creatividad y la experiencia; y los materiales didácticos eran pocos, de bajo costo y de fácil acceso.

Por otra parte, la diversidad estaba presente en las aulas: alumnos con diferentes realidades socioeconómicas, alumnos con deficiencias auditivas, autismo, parálisis, mis hermanos y yo, conformábamos una comunidad estudiantil en donde la diversidad era algo cotidiano y una oportunidad permanente de aprendizaje.

Las percepciones de temor, se fueron rompiendo con el tiempo y con la convivencia. Los trabajos en grupo nos permitieron acercarnos y conocernos, a compañeros y docentes. Por lo que creo que de forma algo empírica, se practicaba lo que Stainbach y Stainbach (1999) han llamado currículo de amigos, enfoque que enfatiza en la orientación a conectar a estudiantes y maestros por medio de la amistad y de relaciones de atención mutua.

El apoyo de mis compañeros y de mis maestros a escala emocional fue fundamental. Sin embargo, las adaptaciones que los docentes realizaban para mí eran principalmente en el 
tamaño de letra de las evaluaciones, evaluaciones orales y en la ampliación de los tiempos de realización de las actividades, por lo que mi madre continuó siendo mi maestra de apoyo, leyendo en voz alta y transcribiendo apuntes y textos para mí.

Aunque mis profesores tenían poca experiencia o ninguna con personas con discapacidad, tenían disposición y entusiasmo para colaborar. Esa actitud generó una comunicación más abierta entre mis padres, los docentes y yo, propiciando la culminación de mis estudios secundarios.

Durante esos años de la secundaria, mis padres buscaron apoyo en el Hellen Kéller (Creado por Decreto Presidencial 16831), institución que daba atención a personas con ceguera en Costa Rica. Aunque nunca hubo una valoración seria y médicamente respaldada por parte de la institución, no me calificaban como ciega por lo que debía esperar para ser receptora de los servicios y ayudas que necesitaba. Gracias a la lucha y persistencia de mis padres, logré asistir a la institución por unas pocas semanas, con el deseo arrollador de aprender cosas que me ayudaran a tener mayor autonomía como el uso del bastón y creyendo que iba a recibir apoyo en mi quehacer académico, pero la realidad con la que me encontré fue muy distinta.

La institución entendía el apoyo a la persona con discapacidad visual, como una ayuda al "pobrecito", enseñando a hacer cajas de cartón o a utilizar un ascensor para ganarse la vida con eso. Como si la capacidad intelectual y las habilidades fueran inexistentes por la ausencia de visión. Era prácticamente nula la coherencia entre las prácticas y actividades institucionales, con los intereses de las personas que deseaban participar de una vida académica común.

Los objetivos y los contenidos del programa de "apoyo" que nos ofrecía el Hellen Kéller, para mis hermanos y para mí, ya habían sido a nivel experiencial, superados. Las actividades sobre temas o habilidades ya aprendidas, el trato marginador y justificador de "Usted no puede", "Sin mí no puede lograrlo", más que un apoyo o colaboración a una situación eran la forma de justificar su trabajo y su incapacidad por atender las verdaderas demandas existentes. 
Teniendo como referente la experiencia vivida con la ONCE y después de una evaluación familiar, coincidimos en que la ausencia de una evaluación de necesidades y la falta de proyección de la institución, generaron inquietud y angustia, en razón de lo cual decidimos seguir el camino como hasta la fecha lo habíamos realizado, adaptándonos y ajustándonos al contexto con afecto y voluntad.

El sueño por encontrar una solución médica que revirtiera o paralizara el avance de la enfermedad, nos llevó en 1993, al Centro Internacional de Retinosis Pigmentaria "Camilo Cienfuegos", en Cuba, el cual nos ofrecía, con mucha incertidumbre, la posibilidad médica de retrasar el proceso degenerativo de la retina. Tomamos como familia la decisión de arriesgar la poca visión que aún teníamos y someternos al tratamiento.

Doce años después de aquella experiencia, desconozco la fiabilidad y validez científica de aquel proceso quirúrgico y terapéutico, al que nos sometimos unos cientos de personas de todo el mundo. Sin embargo, la experiencia me permitió valorar la importancia del vínculo afectivo existente entre mis hermanos y yo, y el objetivo común de no quedarnos paralizados ante las dificultades, de asumir riesgos conjuntamente y de responsabilizarnos de ese tipo de decisiones. También me dio la oportunidad de conocer a personas con retinosis pigmentaria, que, en diferentes contextos y países, se enfrentan con cotidianidad a situaciones similares a las mías. Reconocer que no éramos los únicos luchando por la luz, generaba una sensación de pertenencia y de consuelo. ¿Es entonces necesaria la comparación de situaciones entre los seres humanos y la necesidad de pertenecer a un grupo como forma de encontrar un lugar en el mundo?

En los inicios de la década de 1990, empezaban a gestarse cambios en la consideración de las necesidades especiales en el entorno educativo y unas pocas personas con discapacidad empezaban su camino por las aulas universitarias. Sin embargo, la inexistencia de un marco legal, de una estructura organizativa y de recursos materiales y humanos, constituían la realidad institucional, que condicionaba y limitaba el acceso y participación.

Los docentes universitarios no contaban con ningún tipo de formación o de experiencia en atención a la diversidad, y la distancia entre profesores y alumnos era una cultura institucionalizada, siendo el apoyo docente a la labor del estudiante algo distante y ajeno. La 
mayoría de los profesores se limitaba a impartir clases magistrales, en donde las relaciones docente-alumno, alumno-alumno, eran algo carentes de comunicación.

El ingreso en la Universidad resultaba más individualista, lo que exigía de mí un mayor esfuerzo para integrarme y participar de las actividades de la clase y para cumplir con los objetivos del programa académico. En este sentido, se pone de manifiesto lo citado por Aiscow, M. (2001) en cuanto a que las dificultades educativas se derivan de la interacción de lo que el alumno y la escuela aportan.

Cada vez que entraba en una clase nueva frente a mis compañeros y a mi profesor explicaba brevemente mi situación. Esa explicación pública en parte me ahorraba el tener que explicar individualmente a cada compañero que se me acercaba y por otro lado creo que funcionaba como un destructor confiable de mi miedo al enfrentarme con un entorno nuevo, y del miedo de la gente con respecto a cómo ayudarme.

La mediación de mis padres con los docentes desapareció y era yo la que tenía que enfrentar y resolver las situaciones que se presentaban. Generalmente, solicitaba a mis profesores que me permitieran realizar las evaluaciones en el sitio del aula que yo eligiera y que consideraba más propicio a mi visión, la letra de los textos de los exámenes grande, negra y legible y en algunos casos un poco más de tiempo.

Mis solicitudes no siempre eran aceptadas o recordadas, con frecuencia olvidaban lo solicitado con respecto al texto en letra grande o no aceptaban las consideraciones de tiempo, lo cual me valió perder alguna asignatura, aún dominando la materia.

Las adaptaciones y ajustes de los materiales, durante la época de vida universitaria, exigían más creatividad e incorporación de herramientas tecnológicas, pero básicamente eran los mismos de toda la vida, como grabaciones de textos y ampliaciones de documentos. Recuerdo a mi madre transcribiendo en tinta negra y letra grande estados financieros, fórmulas matemáticas, gráficos y hasta las tablas estadísticas y logarítmicas que se utilizaban en aquellos años. Así, mi madre continuaba siendo mi maestra de apoyo y principal motivadora, siempre diciendo: "usted puede", "siga adelante", "tenga paciencia", "no se desespere", "si siente que lo necesita, descanse", "si quiere, lleve menos asignaturas", pero continué adelante, siempre adelante. 
Durante los primeros años de Universidad, fue difícil practicar un currículo de amigos, los grupos de clase eran mucho más grandes, no siempre matriculábamos los mismos itinerarios y más que solidaridad existía un nivel de competencia muy individual. Sin embargo, con el paso de los años y de la coincidencia ocasional fuimos estableciendo relaciones más sólidas y creo que mi permanencia y mi continuidad en la Universidad eran valoradas por mis compañeros. ¿Era siempre yo la que cambiaba y me ajustaba al entorno o el entorno también? ¿Qué cambios hacía el entorno por mí? Y ¿Debía el entorno cambiar algo?

La cúspide del sueño parecía alcanzada; mi hermano mayor se había graduado de periodista, mi hermano menor de abogado y yo de administradora de empresas. Creo que, en cierta forma, los tres pensamos que el respaldo y el reconocimiento social de un título universitario garantizaban una participación plena en la sociedad.

Una vez finalizada mi carrera universitaria, me entregué al objetivo de buscar empleo. Entregué cientos de currícula vitae y me presenté a muchos procesos de selección de personal, sin tener un resultado positivo. Los comentarios de los empleadores o de los entrevistadores, siempre eran los mismos: "A nosotros no nos sirve una persona que no ve", "nosotros no podemos ayudarle", "su currículo es excelente, pero a nosotros no nos sirve." ¿Servir para qué? Y ¿Por qué no?

Recuerdo una oportunidad en la que había participado en un proceso de selección para trabajar en un banco, en un puesto que consistía en atender dudas a los clientes de servicios financieros. Me habían aplicado evaluaciones médicas, psicométricas, de habilidades y de conocimientos, y había aprobado todas, sin ninguna adaptación y con mucha dificultad para leer, escribir y responder en el tiempo solicitado. La fase final era la entrevista con el jefe de la oficina, pero cuando llegué a la cita, su secretaria me dijo: "él no la puede atender porque no está en la oficina." Supongo que creyó que el no ver implica también no oír, o algo más. El señor estaba ahí y yo misma escuché cuando le decía a su secretaria: "Yo a ella no la quiero, no nos sirve." Después de hacer varias llamadas, la secretaria me dijo: "La atenderé yo, creo que hay un puesto para usted." Me llevó a una central telefónica y me dijo: “¿Usted cree que pueda ser capaz de contestar y pasar llamadas telefónicas?". Ese evidentemente no era el puesto de trabajo para el que yo había concursado y para el cual me habían realizado tantas evaluaciones. Pocas veces en mi vida me había sentido tan indignada, así que le pregunté: “¿Usted cree que si fui a la universidad seis años, si me gradué, si sé usar 
una computadora y una calculadora financiera perfectamente, no podré utilizar una central telefónica?”. Salí de ahí llorando y preguntándome una y mil veces ¿Para qué tanto esfuerzo? ¿Hubiera sido mejor aprender lo que me proponía el Instituto Hellen Keller y hacer cajas o ser ascensorista? ¿Por qué nadie me da la oportunidad de demostrar que puedo hacer las cosas? ¿Para qué me habían evaluado tanto y me habían aprobado? Y ¿cómo encontrar sentido a todo eso que me sucedía?

Había pasado meses en esa búsqueda incansable de trabajo y resistiendo situaciones como esa. Mi estado anímico empezaba a deteriorarse. Mis estudios de administración de empresas me permitían entender el razonamiento de aquellos empleadores: un empleado lento, menos productivo en horas de trabajo, solicitando ayuda, no era lo óptimo y lucrativamente correcto. Sin embargo, yo me resistía a esa justificación, porque mi rendimiento en el aula muchas veces había tenido que ser superior al de los demás, ¡cuántas evaluaciones había realizado sin consideraciones de tiempo, letra o iluminación, luchando en contra de mi propia limitación, esforzando mi vista al máximo y a pesar de no haber contado con las condiciones mínimas requeridas había logrado mejores resultados que muchos de mis compañeros!

Consciente de mi situación, de buscar una nueva alternativa y de vivir en un mundo de acelerados cambios era conveniente proseguir con mi desarrollo profesional y buscar en el plano personal una mayor autonomía. Así una beca me dio la oportunidad de cursar una maestría, en la Universidad Internacional de Andalucía, Sede Iberoamericana Santa María de la Rábida.

La maestría que cursaría se llamaba Maestría en Formación y Desarrollo de los Recursos Humanos, y pensé que el ámbito de la formación en la empresa podía ser más accesible para mí, no respondía tanto a estándares de productividad por tiempo y podría aplicar mis conocimientos en administración.

Durante la maestría la experiencia con los docentes fue fundamentalmente, un asunto de explicación de mi situación personal, los ajustes o adaptaciones curriculares, prácticamente fueron innecesarios. Ya que la metodología de los módulos consistía en participación en clase y trabajos individuales o grupales. 
Vivía con el resto de mis compañeros en el campus universitario, por lo que el entorno poco a poco se fue convirtiendo como en mi casa, era un entorno relativamente controlado, en donde todos estábamos sujetos a los mismos horarios y disciplinas. Por lo que pude experimentar mayores niveles de movilidad en cuanto a desplazamientos y decisiones, generando altos grados de satisfacción, de sensación de pertenencia a una comunidad y de ajuste con el medio.

Pensé que la seguridad en mí misma y la superación de mis propias estructuras y barreras mentales, producto de la experiencia, serían un elemento a favor, en mi nueva búsqueda de trabajo. Pero a mi regreso a Costa Rica, la realidad social, cultural y los modelos mentales institucionalizados, seguían siendo los mismos. Con los meses, la ilusión de encontrar empleo fue desvaneciéndose y empezando a generar altos grados de frustración, insatisfacción y aislamiento.

El Ministerio de Educación Pública, las universidades estatales y el Instituto Nacional de Aprendizaje, asumieron un rol de cambio, en la conciencia social, en relación con las personas con discapacidad. Como parte de este proceso de aceptación y reconocimiento social y legal de la igualdad de oportunidades, se promulgó en 1996 la "Ley de igualdad de oportunidades de las personas con discapacidad" (Ley N. ${ }^{\circ} 7600$ ). Congruentemente, Costa Rica había ratificado la "Convención Interamericana para la eliminación de todas las formas de discriminación contra las personas con discapacidad", acordada por la Asamblea General de la OEA, el 7 de junio de 1999, en Ciudad de Guatemala.

Habían pasado varios años desde la promulgación de la Ley 7600 y aunque reconozco la importancia de la Ley como punto de partida para generar un cambio y el aporte de esta en materia educativa, pero en el proceso de incorporación al mercado laboral parecía no haber cambiado muchas cosas en la sociedad. ¿Qué había cambiado en el sistema educativo? Y, ¿cómo se proyectaba el cambio en el sistema educativo a la sociedad?

En relación con el trabajo, la Ley dice:

Artículo 23.- Derecho al trabajo

El Estado garantizará a las personas con discapacidad, tanto en zonas rurales como urbanas, el derecho de un empleo adecuado a sus condiciones y necesidades 
personales. (Ley de Igualdad de Oportunidades de las Personas con Discapacidad No7600, 1996)

Asimismo, el artículo 24 se refiere a los actos de discriminación en la selección de personal, en el acceso y la utilización de los recursos productivos. El artículo 26 se refiere al asesoramiento a los empleadores por parte del Estado.

A pesar de la existencia de la Ley y del reconocimiento en los artículos mencionados de la garantía del Estado en el derecho al trabajo, mis intentos fueron en vano. Los procesos de selección de personal en los que participé nunca fueron supervisados por ningún ente estatal.

Los artículos 62 y 63 de la Ley N. ${ }^{\circ} 7600$ se refieren a la multa que se impondrá por limitar la accesibilidad de las personas con discapacidad, multa que se fija en la mitad de un salario mínimo. ¿En el caso de la accesibilidad al trabajo será la mitad de un salario mínimo, una cifra comprometedora o responsabilizadora para un empleador? ¿Qué mecanismo permite, supervisa y ejecuta la imposición de esa multa? ¿Por qué el Estado no es el primer empleador de personas con discapacidad? Y ¿cómo se atreve el Estado a garantizar derecho al trabajo sin generar él mismo las alternativas?

Busqué en el Ministerio de Trabajo y Seguridad Social y en la Defensoría de los Habitantes, asesoría y apoyo en mi proceso de incorporación al mercado laboral. En la Unidad de Discapacidad del Ministerio de Trabajo y en la Defensoría de los Habitantes, los temas de discapacidad son atendidos únicamente por una persona; desconozco el presupuesto y los recursos de los que disponen estas oficinas y de los mecanismos de acción al no poder dar respuesta a mis necesidades.

Pero las dos instituciones reconocieron no tener los mecanismos suficientes para poder contribuir y garantizar lo estipulado en la Ley. ¿Son estas instancias gubernamentales simplemente creadas para justificar intereses y posturas políticas amparadas en la igualdad y la democracia? ¿Hay un acto contradictorio y contraproducente, al generar el sistema educativo expectativas que resultan insatisfechas en el campo laboral, y se produzca una obstaculización de la devolución de la inversión social? 
Mi deseo por cambiar y mejorar la calidad de vida de aquellos que por una u otra razón se sienten aplastados y excluidos por un sistema que utiliza cada vez con más frecuencia el discurso democratizador de la igualdad y que se resiste a la apertura y el cambio en prácticas concretas, me condujo a replantearme el camino.

El sistema educativo había sido mi único y gran intermediario entre el mundo y yo. A pesar de las dificultades que siempre había encontrado, mi esfuerzo y voluntad habían tenido un resultado, más allá de la parálisis en la que me encontraba sin poder acceder al mundo del trabajo. Pensé que era necesario volver al sistema educativo y generar desde ahí el cambio.

Un doctorado, un proyecto de doctorado que tuviera como tema de investigación, la respuesta a aquellas preguntas y situaciones que había tenido que enfrentar, eran el camino, quizá el único, al que podía pretender acceder.

Después de haberme postulado a todas las becas que encontré en Internet, en el mes de marzo del 2004 la Agencia Española de Cooperación Internacional me comunicó que yo era una de las personas elegidas como becaria y que podría cursar el programa de doctorado que había elegido en la Universidad de Barcelona. Había pasado tantos meses deseando no ver otro amanecer que cuando llegó la comunicación de la beca tuve la certeza de que volver a Barcelona era lo correcto, por algo se abrían las puertas hacia fuera. Con cierta extrañeza pensé: "Es otro país el que me da la oportunidad de seguir luchando y viviendo."

El hacer el doctorado por un lado implicaba un gran sueño: por otro, el temor, casi terror de asumir un compromiso social y generar un cambio, y de tener que enfrentarme con hacer mi vida fuera de la casa de mis padres, sin mi familia y en una ciudad a varios miles de kilómetros de distancia. Antes de ir a Barcelona, era urgente y necesario aprender a movilizarme sola y conseguir la autonomía que siempre había soñado.

A diferencia de la Rábida, en Huelva, donde había realizado la maestría, no sería un entorno relativamente controlado en el que tendría que movilizarme, ni serían pocos meses. Seria un periodo de dos años mínimo y tendría que moverme por la ciudad.

En varias ocasiones había buscado en Costa Rica, un profesor de orientación y movilidad que estuviera dispuesto a darme clases, pero el único que había intentaba siempre hacerme 
pasar por todos los trámites burocráticos que al final no me conducían a nada y nunca estuvo dispuesto a darme clases privadas. Pero ante mi decisión de viajar a Barcelona, volví a intentarlo. Recuerdo esa tarde que llamé buscando información y me pasaron al teléfono a una chica llamada Silvia. Era una nueva profesora y al explicarle mi situación, de inmediato estuvo dispuesta a darme clases.

Toda mi vida había caminado tomada del brazo de alguien que me ayudaba como guía. Mis primeras clases de bastón fueron cerca de mi casa, en lugares conocidos desde hacía mucho tiempo atrás. Más allá de aprender la técnica y la coordinación necesaria entre bastón y pies, para mí fue aprender a caminar de nuevo.

Al inicio, me daba miedo todo lo que iba percibiendo y lo que no percibía también, a pesar de ser un entorno relativamente conocido el caminar sola implicaba conocerlo de una forma diferente. Ya en la tercera sesión, Silvia caminaba unos cuantos metros atrás de mí y los recorridos eran más largos, pero la sensación de saber que ella estaba atrás era como la de un ángel que me cuidaba. Más pronto de lo que yo estuve preparada para enfrentarlo me dijo: "Mónica, te espero en la parada del bus." Era tiempo de que yo asumiera sola el reto y caminara sin ella atrás. Así fuimos avanzando, hacer nuevos recorridos, aprendiendo a ir en transporte público.

Dos meses y medio después, el bastón era casi parte de mi cuerpo. Sin notarlo, el aprender a caminar me había dado muchísima confianza en mí misma, había superado en mucho mis inseguridades y hasta sentía que la forma de percibirme y en que me percibía la gente era diferente. Notablemente, era más fácil pedir ayuda y era más fácil recibirla también.

Mis padres celebraron la noticia de la beca, pero les causaba preocupación pensar en mi traslado, instalación y supervivencia en Barcelona, ante lo que me propusieron viajar conmigo al menos mientras me adaptaba. Pero mi decisión estaba clara y así la respetaron. Yo viajaría sola y me enfrentaría con todo lo que tuviera que enfrentarme sola. Les pedí que no fueran siquiera al aeropuerto, no quería llorar, no quería sentir la despedida, necesitaba estar tranquila, alerta a cualquier situación que se presentara. Mi madre se negó rotundamente a no acompañarme hasta el aeropuerto, recuerdo que me dijo: "Yo la parí y la acompaño hasta dónde me da la gana, no voy a llorar porque si eso es lo que usted quiere, 
sé que lo va a lograr." Una vez más me demostraba su entereza, su fuerza, su confianza y su amor.

Esa mañana de setiembre, después de despedirme de mi madre, subí al avión como lo había deseado tranquila y con una sensación de alegría indescriptible. No miré, por la ventana, como usualmente lo hacía cuando salía del país, buscando aquellas montañas maravillosas que rodeaban la ciudad, muchas veces había pensado en lo maravilloso de ese paisaje y en la limitación que encerraba no mirar más allá de las montañas. Me esperaban muchas horas de viaje y en lo único que pensaba era en que volaba en busca de un sueño y en que mi mirada de la vida de nuevo empezaba a cambiar. A mi llegada a Barcelona, intenté mirar por la ventanilla del avión, cuando logré con dificultad divisar algo de la ciudad y el Mediterráneo, mis lágrimas empezaron a salir. Había terminado el viaje y ahora empezaba todo.

En las primeras semanas, moverme por la ciudad, ir a la Universidad, al supermercado, al banco, al Centro, me era muy difícil. A pesar de mi disposición y alegría en el proceso de aprendizaje de todo aquello que me rodeaba, había también un alto grado de estrés, de angustia y de miedo. Había un exceso de información, que por momentos me hacía sentir saturada. Era todo nuevo, desde como encontrar un vaso, una cuchara o un plato en mi nueva casa, los pasos, obstáculos y luces que podía determinar en los que serían mis recorridos habituales, el establecer relaciones con profesores y compañeros, el hablar y pedir ayuda en la calle, implicaban percibir cada día como un reto.

Han pasado varios meses desde mi llegada, esas cosas iniciales que me causaban angustia y miedo, las asumo con más tranquilidad. Conozco más la ciudad y aprendo nuevos recorridos con más facilidad. No supero por completo el miedo, lo asumo como un motivador de dinamismo. Reconozco haber logrado niveles de autonomía al movilizarme, que si no hubiera sido por la presión de las circunstancias no hubiera enfrentado nunca. Esos niveles de autonomía me han permitido conocerme y sentirme satisfecha de cada paso dado, me han abierto un mundo de posibilidades más allá de la simple movilización, han abierto mi mente al cambio y al asumir el cambio como algo necesario para estar en movimiento.

En el doctorado, la formación humanística, la experiencia profesional y la sensibilidad, de mis compañeros y docentes, el establecer vínculos afectivos con los que me rodean, me han 
permitido descubrir en el día a día, la necesidad permanente de seguir adelante, de apreciar el entorno y de reconocer diversas posibilidades de aprendizaje. Poco a poco me han dado la confianza para empezar a investigar sobre lo que me trajo hasta aquí.

Las asignaturas del primer año del programa de doctorado me han permitido romper con el miedo a buscar en mi memoria, a investigar en mi pasado, a descubrir y reconocer los elementos fundamentales de mis procesos de cambio, a mirar en la complejidad del mundo en el que vivo y de la forma en la que estructuro, construyo y percibo lo que me rodea, lo que soy y en la forma en la que me siento incluida o excluida de la sociedad. Admito que más que respuestas en este proceso, he ido encontrando nuevas preguntas que me conducen a nuevas y más profundas reflexiones.

Cuando llegué a Barcelona e inicié el doctorado, creí llegar con un tema y objetivos de tesis claramente definidos. Pero unos cuantos meses después, mi percepción, interpretación y el rumbo de aquel tema estructurado han ido cambiando.

Intentando comprender todo ese cambio que estoy viviendo y de encontrar mi propia voz en ese cambio, escribí hace unos días lo siguiente:

"Los silencios no pueden hacerse invisibles, en la presencia o en la ausencia, porque la dicotomía del discurso es parte de la vida.

Reconozco la muerte como el principio del renacer y de la continuidad y en el nacer la limitación de la existencia.

No soy madre pero siento, desde y en mis entrañas, la fuerza de la tristeza y la alegría, que quita y da la vida.

Para ser plena hay que quedarse vacía; para olvidar hay que tener algo que recordar, para conocer la sombra hay que conocer la luz.

Descubro que los esquemas se quiebran, que las estructuras se construyen, que las palabras se inventan, y que el rumbo se cambia.

No hay silencios eternos, ni tiempos perfectos, ni verdades completas; hay normas, requisitos, trampas, emociones y sentimientos; y cuando el rumbo se acaba, hay arenas sin huellas". 
Ese proceso de identificar y encontrar nuevos caminos y planteamientos de mi proyecto y de mi vida, han generado un torbellino que a veces en las discusiones de las sesiones del doctorado parecen no encajar en algo concreto.

Ha sido difícil no oponer resistencia a ese torbellino y dejarme caer sin temor, pero poco a poco he ido rompiendo con aquella intención de buscar resultados exactos, concretos, con esquemas perfectos, de autonomías desvinculantes del entorno y de la gente que me rodea.

Por otro lado, entiendo y reconozco en la educación el poder como medio para generar cambios trascendentales en todos los sistemas y subsistemas de la sociedad. No obstante, reconozco las posibles limitaciones de las que goza este poder, el cual no se circunscribe meramente al ámbito educativo, sino que surge y se deriva de las relaciones existentes entre lo pedagógico, lo jurídico y lo sanitario; de las relaciones que se median en un contexto y desde la construcción mental individual y social.

A lo largo del camino de la vida, que llevo recorrido, he aprendido a mirar las dificultades como retos, las barreras como peldaños de una escalera, y los malos momentos como espacios para la gestación de un nuevo sueño. También he aprendido que la autodeterminación y la autonomía están en función de la necesidad, del contexto y de la voluntad.

Mi percepción y mi conocimiento de mi propia identidad han cambiado y asumo mi autonomía en la comprensión y el reconocimiento de la necesidad de aquellos que me acompañan por el camino. Es así como reinicio el camino con un cambio de conciencia, en dónde la percepción e interpretación parten de lo invisible e indivisible de las relaciones, del origen del vínculo y el saber que hay en la diferencia, y no desde el discurso de la igualdad con el que inicié este texto.

Continúo el camino sin despreciar o valorar lo que tenía construido, pero asumo nuevos planteamientos en la búsqueda de respuestas y de sentido: ¿Dar humanidad? ¿Producir conciencia? ¿Generar un cambio? 


\section{Referencias}

Ainscow, M. (2001). Desarrollo de escuelas inclusivas. Ideas, propuestas y experiencias para mejorar las instituciones escolares. Madrid: Narcea.

Stainbach, S., Stainbach, W. (1999). Aulas inclusivas. Madrid: Narcea.

Asamblea Legislativa, República de Costa Rica. (1949). Constitución Política de la República de Costa Rica. Versión Web 2004. www.asamblealegislativa.go.cr

Asamblea Legislativa, República de Costa Rica. (1996). Ley de Igualdad de Oportunidades de las personas con discapacidad. Ley 7600. http://www.cnree.go.cr/legislacion/legislacion.htm

Presidencia, República de Costa Rica. (1985). Creación del Instituto de Rehabilitación y Formación

Hellen Keller.

Decreto

16831. http://www.cnree.go.cr/legislacion/legislacion.htm

Asamblea General, Organización de Naciones Unidas. (1948). Declaración Universal de los Derechos Humanos. Suiza: ONU. 